\title{
Prognostic value of the triglyceride-glucose index among non-diabetic patients with acute myocardial infarction at one-year follow-up
}

\author{
Dominika Drwiła' , Paweł Rostoff1,2, Grzegorz Gajos',2, Jadwiga Nessler1,2, Ewa Konduracka1,2 \\ 'Department of Coronary Disease and Heart Failure, John Paul II Hospital, Kraków, Poland \\ ${ }^{2}$ Department of Coronary Disease and Heart Failure, Institute of Cardiology, Jagiellonian University Medical College, Kraków, Poland
}

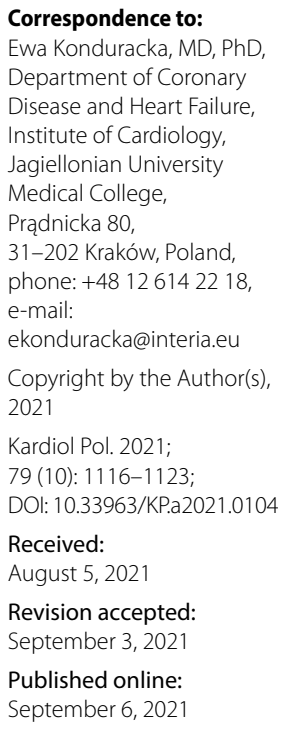

Correspondence to:

Ewa Konduracka, MD, PhD, Department of Coronary

Disease and Heart Failure,

Institute of Cardiology,

Jagiellonian University

Medical College

Prądnicka 80,

31-202 Kraków, Poland,

phone: +481261422 18,

e-mail:

ekonduracka@interia.eu

Copyright by the Author(s), 2021

Kardiol Pol. 2021;

79 (10): 1116-1123.

DOI: 10.33963/KP.a2021.0104

Received:

August 5, 2021

Revision accepted:

September 3, 2021

Published online:

September 6, 2021

\begin{abstract}
A B S TR A C T
Background: The triglyceride-glucose index (TyG index) is a novel metabolic marker initially used as an indicator of insulin resistance. Recently, its use as a cardiovascular risk factor has been taken into consideration; however, there is a shortage of evidence for its clinical importance.
\end{abstract}

Aims: The study aimed to assess the relationship between the TyG index $=\ln$ (fasting triglyceride $[\mathrm{mg} / \mathrm{dl}] \times$ fasting glucose $[\mathrm{mg} / \mathrm{dl}] / 2$ ) and the incidence of major adverse cardiovascular events (MACE) at a 1-year follow-up among non-diabetic patients with acute myocardial infarction (MI). In addition, the predictive value of the TyG index concerning all-cause mortality in the study group was evaluated.

Methods: For the study, 1340 non-diabetic patients with acute MI (median age, 67 years, $70.4 \%$ male) were consecutively enrolled between 2013 and 2019. The fasting lipid profile and the fasting glucose level were assessed within 24 hours of admission.

Results: MACE occurred in $8.13 \%(n=109)$ of the study group, whereas 1 -year mortality rate was $14.5 \%$ $(n=195)$. There was no difference in the median TyG index value among patients with and without incidence of MACE at a 1-year follow-up (8.73 [8.36-9.08] vs. 8.81 [8.5-9.17]; $P=0.09$ ). Moreover, the TyG index was not a predictor of these events $(P=0.06)$. In multivariable regression analysis, only previously diagnosed coronary artery disease (CAD) was an independent predictor of MACE (odds ratio [OR], 1.54; $95 \% \mathrm{Cl}, 1.02-2.32 ; P=0.03)$. Finally, the TyG index was not an indicator of all-cause mortality $(P=0.25)$.

Conclusions: The TyG index should not be used as a predictor of MACE and all-cause mortality among non-diabetic patients with $\mathrm{Ml}$ at a 1-year follow-up.

Key words: all-cause mortality, MACE, myocardial infarction, triglyceride-glucose index

Kardiol Pol 2021; 79, 10: 1116-1123

\section{INTRODUCTION}

In modern non-invasive cardiology, great emphasis is placed on the prevention of coronary artery disease (CAD) which can manifest as acute or chronic coronary syndromes and/or heart failure. There are several unmodifiable and modifiable cardiovascular risk factors, but considerable research concerning new factors has been conducted worldwide, and numerous previous studies reveal that insulin resistance (IR) is significantly related to the occurrence of CAD among diabetic and non-diabetic patients $[1,2]$. A practical indicator to measure IR is the Homeostasis Model Assessment of Insulin Resistance (HOMA-IR) test; however, its usefulness is limited due to the necessity of measuring the level of insulin, which is not always possible in the circumstances that prevail. Recently, the triglyceride-glucose index (TyG index) has been suggested as a new tool to measure IR [3].

The primary aim of the study was to examine the association between TyG index value and the occurrence of major adverse cardiovascular events (MACE) at a 1-year follow-up among non-diabetic patients with acute myocardial infarction (MI). The secondary aim was the evaluation of its predictive value concerning 1-year mortality in the study group.

\section{METHODS}

This was a cohort study based on data collected from the medical records of 2300 patients with acute $\mathrm{Ml}$ admitted to 
WHAT'S NEW?

The triglyceride-glucose index (TyG index) is a metabolic marker recently considered as a novel cardiovascular risk factor. In our study, we assessed a potential relationship between the TyG index and the incidence of major adverse cardiovascular events (MACE) and all-cause mortality at a 1-year follow-up among non-diabetic patients with acute myocardial infarction (MI). We demonstrated no clinical evidence for the importance of this marker. The TyG index value does not appear to predict the incidence of MACE and all-cause mortality among non-diabetic patients with MI at a 1-year follow-up.

our hospital between 2013 and 2019. Patients who met inclusion criteria were consecutively recruited for the study.

Inclusion criteria were diagnosis of STEMI (ST-segment elevation myocardial infarction) or NSTEMI (nonST-segment elevation myocardial infarction), coronary angiography undergone on admission with the presence of hemodynamically relevant atherosclerosis, and full medical documentation. Exclusion criteria were diabetes or prediabetes diagnosed prior to admission, use of glucose-lowering drugs or insulin, $\mathrm{Ml}$ with non-obstructive CAD (MINOCA), acute heart failure on admission, and incomplete medical records.

All the patients had undergone emergency coronary angiography followed by percutaneous angioplasty with stent implantation or coronary artery bypass grafting if indicated. CAD severity was assessed with the Gensini score system [4] and performed by 2 experienced invasive cardiologists. Additionally, basic blood tests and echocardiography were performed. Data concerning MACE and 1-year mortality were obtained via telephone consultations scheduled with the patients or their families 1 year after MI.

\section{Laboratory tests}

Lipid profile and blood fasting glucose level (FGL) were evaluated from fasting blood samples collected within 24-hours of admission. Lipid profile was measured by the direct enzymatic colorimetric method, using commercial in vitro diagnostic devices (Cobas C, Roche, Basel, Switzerland), whereas FGL was measured by the enzymatic hexokinase technique, using in vitro equipment (Cobas $C$, Roche, Basel, Switzerland). The TyG index was calculated manually using the following formula: TyG index = In (fasting triglyceride $[\mathrm{mg} / \mathrm{dl}] \times$ fasting glucose $[\mathrm{mg} / \mathrm{dl}] / 2$ ) [5] .

\section{Definitions}

Acute MI was defined according to the European Society of Cardiology guidelines, the Third (2012) or Fourth (2018) Universal Definition of Myocardial Infarction [6, 7]. MACE was a composite of myocardial infarction, in-stent restenosis, unstable angina, stroke or transient ischemic attack, and hospitalization due to heart failure. Being overweight was defined as a body mass index (BMI) ranging from 25 to $29.9 \mathrm{~kg} / \mathrm{m}^{2}$, whereas obesity was determined as a BMI of $30 \mathrm{~kg} / \mathrm{m}^{2}$ or higher. Diabetes was defined according to guidelines valid on the day of hospital admission [8]. Furthermore, in the current report, impaired glucose tolerance or impaired fasting glucose before hospital admission were reported as prediabetes. Acute heart failure was diagnosed in the patients admitted with signs and symptoms of heart failure due to decompensation of pre-existing cardiomyopathy or a new-onset heart failure caused by MI. A blood pressure of 140/90 $\mathrm{mm} \mathrm{Hg}$ or higher, on at least 2 separate measurements, or the use of antihypertensive drugs were defined as hypertension.

\section{Ethics}

The study protocol was approved by the local Ethics Committee (Jagiellonian University Medical College - KBET: 1072.6120.189.2020 to EK). Each study participant provided written informed consent before enrolment.

\section{Statistical analysis}

All calculations were made using the STATISTICA 13.3 software package (TIBCO Software Inc., Palo Alto, CA, USA). A 2-sided $P$-value $<0.05$ was considered to be statistically significant. Continuous variables were expressed as medians, using the first and third quartiles, while categorical variables were shown as numbers and percentages. The normality of variables was assessed with the Shapiro-Wilk test. The Mann-Whitney and Kruskal-Wallis tests were used for non-normally distributed continuous variables, and categorical variables were compared using the Chi-square test. Stepwise logistic regression analysis was performed for determining the independent predictors of MACE and all-cause mortality. The final multivariable model included variables that were significant univariate predictors.

\section{RESULTS}

\section{Patients}

For our initial analysis, we enrolled 2300 patients admitted to our department. A total of 807 patients were excluded due to diabetes or prediabetes diagnosed prior to admission; 153 patients were excluded because of incomplete medical records. In addition, among those excluded, there were 18 cases of acute heart failure on admission. Finally, we analyzed data collected from 1340 patients at a median age of 67 years, among whom $70.4 \%$ were male. Most of the patients were overweight, with a median BMI of $26 \mathrm{~kg} / \mathrm{m}^{2}$. For $66 \%$ of them, Ml was the first manifestation of CAD. Baseline characteristics of the study population are shown in Table 1. 
Table 1. General characteristic of the study group

\begin{tabular}{|c|c|c|c|c|}
\hline Variables & $\begin{array}{l}\text { All study patients } \\
\qquad n=1340\end{array}$ & $\begin{array}{c}\text { Men } \\
n=944\end{array}$ & $\begin{array}{l}\text { Women } \\
n=396\end{array}$ & $P$-value \\
\hline Age, years ${ }^{a}$ & $67(59-76)$ & $64(58-74)$ & $72(64-80)$ & $<0.01$ \\
\hline $\mathrm{BMI}, \mathrm{kg} / \mathrm{m}^{2 \mathrm{a}}$ & $26(24-29)$ & $26(24-29)$ & $26(23-29)$ & 0.06 \\
\hline First episode of MI, $\mathrm{n}(\%)$ & $887(66.2)$ & $614(65)$ & $273(69)$ & 0.16 \\
\hline STEMI, n (\%) & $587(43.8)$ & $425(45)$ & $162(40.9)$ & 0.16 \\
\hline NSTEMI, n (\%) & $752(56.2)$ & $519(55)$ & $234(59.1)$ & \\
\hline Gensini score & $50(28-86.5)$ & $56(32-88)$ & $40(24-81)$ & 0.08 \\
\hline Hypertension, n (\%) & $1073(80)$ & 748 (79) & $325(82)$ & 0.2 \\
\hline $\mathrm{eGFR}, \mathrm{ml} / \mathrm{min} / 1.73 \mathrm{~m}^{2 \mathrm{a}}$ & $59(48-69.5)$ & $56(47-65)$ & $65.5(55-79.5)$ & $<0.01$ \\
\hline $\mathrm{FGL}, \mathrm{mmol} / \mathrm{l}^{\mathrm{a}}$ & $6.6(5.7-7.9)$ & $6.6(5.7-7.8)$ & $6.8(5.8-8)$ & 0.08 \\
\hline \multicolumn{5}{|l|}{ Lipid profile } \\
\hline $\mathrm{LDL}-\mathrm{C}, \mathrm{mmol} / \mathrm{l}^{\mathrm{a}}$ & $2.8(2.1-3.6)$ & $2.7(2.1-3.6)$ & $2.9(2.2-3.6)$ & 0.09 \\
\hline $\mathrm{HDL}-\mathrm{C}, \mathrm{mmol} / \mathrm{I}^{\mathrm{a}}$ & $1.2(0.98-1.4)$ & $1.1(0.95-1.4)$ & $1.2(1-1.5)$ & $<0.01$ \\
\hline Non-HDL-C, mmol//a & $3.1(2.5-4)$ & $3.1(2.4-4)$ & $3.2(2.6-4)$ & 0.08 \\
\hline $\mathrm{TC}, \mathrm{mmol} / \mathrm{l}^{\mathrm{a}}$ & $4.4(3.7-5.2)$ & $4.3(3.6-5.2)$ & $4.6(3.8-5.3)$ & $<0.01$ \\
\hline $\mathrm{TG}, \mathrm{mmol} / \mathrm{l}^{\mathrm{a}}$ & $1.2(0.95-1.6)$ & $1.2(0.93-1.6)$ & $1.3(0.98-1.6)$ & 0.55 \\
\hline TyG index value ${ }^{a}$ & $8.8(8.5-9.1)$ & $8.8(8.5-9.1)$ & $8.8(8.5-9.2)$ & 0.2 \\
\hline \multicolumn{5}{|l|}{ Medical therapy prior to admission } \\
\hline Statins, n (\%) & $1103(82)$ & $765(81)$ & $338(85)$ & 0.14 \\
\hline Fibrates, n (\%) & $36(2.7)$ & $26(2.8)$ & $10(2.5)$ & 0.2 \\
\hline ACEI/ARB, $n(\%)$ & $1099(82)$ & $782(83)$ & $317(80)$ & 0.1 \\
\hline B-adrenolitics, n (\%) & $576(43)$ & $415(44)$ & $161(41)$ & 0.12 \\
\hline Calcium blockers, n (\%) & $1072(80)$ & $764(81)$ & $308(78)$ & 0.14 \\
\hline ASA, n (\%) & $498(37)$ & $363(38)$ & $135(34)$ & 0.09 \\
\hline Clopidogrel, n (\%) & $25(1.9)$ & $17(1.8)$ & $8(2)$ & 0.4 \\
\hline Occurrence of MACE at 1-year follow-up, n (\%) & $109(8.13)$ & $78(8.2)$ & $31(7.8)$ & 0.79 \\
\hline In-hospital mortality, n (\%) & $22(1.6)$ & $14(1.5)$ & $8(2)$ & 0.48 \\
\hline One year mortality, n (\%) & $195(14.5)$ & $130(13.8)$ & $65(16.4)$ & 0.21 \\
\hline
\end{tabular}

aData are shown as median (interquartile range) unless otherwise indicated. $P<0.05$ was considered significant

Abbreviations: ACEI, angiotensin-converting enzyme inhibitor; ARB, angiotensin receptor blocker; ASA, aspirin; BMI, body mass index; CAD, coronary artery disease; eGFR, estimated glomerular filtration rate; FGL, fasting glucose level; HDL-C, high-density lipoprotein cholesterol; LDL-C, low-density lipoprotein cholesterol; MACE, Major Adverse Cardiovascular Events; MI, myocardial infarction; non-HDL-c, non-high-density lipoprotein cholesterol; NSTEMl; non-ST segment elevation myocardial infarction; STEMI,

ST-segment elevation myocardial infarction; TC, total cholesterol; TG, triglyceride; TyG index, triglyceride-glucose index

\section{Analysis of MACE}

MACE occurred in $8.13 \%(n=109)$ of the study group. There were 35 cases of Ml, 19 cases of in-stent restenosis, 49 cases of unstable angina, 4 cases of stroke or transient ischemic attack, and 13 hospitalizations due to heart failure. Furthermore, among these cases, there were 12 patients who developed 2 incidents of MACE at a 1-year follow-up, and there were 5 cases of unstable angina and in-stent restenosis, 5 cases of Ml, and in-stent restenosis, and 2 of myocardial infarction and hospitalization due to heart failure.

Analysis of the groups of patients, with and without incidence of MACE at a 1-year follow-up, revealed that there were no statistically significant differences in median age, ejection fraction, BMI, Gensini score, glucose, high-density lipoprotein cholesterol (HDL-C), the TyG index value, the occurrence of hypertension, or sex, and lipid-lowering therapy prior to admission. The patients with incidence of MACE had lower low-density lipoprotein cholesterol (LDL-C), non-high-density lipoprotein cholesterol (nonHDL-C), total cholesterol (TC), triglycerides (TG), and estimated glomerular filtration rate (eGFR). Moreover, $46.8 \%$ of them had been diagnosed with CAD prior to admission, whereas in the second group this was only $32.6 \%$. Detailed demographic and clinical characteristics of those groups are presented in Table 2.

\section{Univariate and multivariable regression analysis of MACE}

Univariate regression analysis showed that previously diagnosed CAD, eGFR, LDL-C, and TC were significant predictors of MACE. However, in the multivariable model, only previously diagnosed CAD proved to be an independent predictor (odds ratio [OR], $1.54 ; 95 \% \mathrm{Cl}, 1.02-2.32 ; P=0.03$ ). The TyG index was not an indicator of MACE in the study group $(P=0.06)$. The significant predictors of MACE are presented in Table 3.

\section{Patients with potential glucose metabolism disorders}

To deepen our analysis, we divided the patients according to their glycemic control status into 2 groups: one with a lower fasting glucose level (FGL $<7.8 \mathrm{mmol} / \mathrm{l})$ and the other with potential, previously undiagnosed, glucose metabolic disorder or stress hyperglycemia caused by MI (FGL $\geq 7.8 \mathrm{mmol} / \mathrm{l}$ ). Hyperglycemia occurred in $25.2 \%$ of the patients $(n=338)$. There was a difference in medians 
Table 2. Demographic and clinical characteristics of patients with and without incidence of MACE in one year follow-up

\begin{tabular}{|c|c|c|c|}
\hline Variables & $\begin{array}{l}\text { Patients with incidence of MACE at } \\
1 \text {-year follow-up } n=109\end{array}$ & $\begin{array}{l}\text { Patients with no incidence of MACE } \\
\text { at } 1 \text {-year follow-up } n=1231\end{array}$ & $P$-value \\
\hline Male sex, $\mathrm{n}(\%)$ & $78(71.5)$ & $866(70.3)$ & 0.8 \\
\hline Age, years ${ }^{a}$ & $67(62-79)$ & $67(59-76)$ & 0.15 \\
\hline $\mathrm{BMI}, \mathrm{kg} / \mathrm{m}^{2 \mathrm{a}}$ & $25.8(23.2-29.4)$ & $26.3(23.8-29)$ & 0.6 \\
\hline CAD diagnosed prior to admission, $\mathrm{n}(\%)$ & $51(46.8)$ & $402(32.6)$ & $<0.01$ \\
\hline Ejection fraction, $\%^{\mathrm{a}}$ & $50(35-55)$ & $50(35-60)$ & 0.7 \\
\hline Hypertension, n (\%) & $86(78.9)$ & $987(80.2)$ & 0.74 \\
\hline Gensini score & $58(24-96)$ & $48(28-96)$ & 0.85 \\
\hline eGFR, $\mathrm{ml} / \mathrm{min} / 1.73 \mathrm{~m}^{2 \mathrm{a}}$ & $54.9(47.3-64.8)$ & $59.2(48.4-70)$ & 0.04 \\
\hline $\mathrm{FGL}, \mathrm{mmol} / \mathrm{l}^{\mathrm{a}}$ & $6.9(5.9-8)$ & $6.6(5.7-7.8)$ & 0.18 \\
\hline $\mathrm{FGL} \geq 7.8 \mathrm{mmol} / \mathrm{l}, \mathrm{n}(\%)$ & $32(29.3)$ & $306(24.8)$ & 0.29 \\
\hline $\mathrm{LDL}-\mathrm{C}, \mathrm{mmol} / \mathrm{I}^{\mathrm{a}}$ & $2.45(1.96-3.44)$ & $2.8(2.15-3.6)$ & $<0.01$ \\
\hline $\mathrm{HDL}-\mathrm{C}, \mathrm{mmol} / \mathrm{I}^{\mathrm{a}}$ & $1.18(0.99-1.48)$ & $1.17(0.98-1.41)$ & 0.56 \\
\hline Non-HDL-C, mmol//a & $2.92(2.26-3.69)$ & $3.18(2.53-4.08)$ & $<0.01$ \\
\hline $\mathrm{TC}, \mathrm{mmol} / \mathrm{l}^{\mathrm{a}}$ & $4.06(3.41-4.9)$ & $4.4(3.76-5.26)$ & $<0.01$ \\
\hline $\mathrm{TG}, \mathrm{mmol} / \mathrm{l}^{\mathrm{a}}$ & $1.13(0.9-1.44)$ & $1.26(0.96-1.68)$ & $<0.01$ \\
\hline TyG index ${ }^{a}$ & $8.73(8.36-9.08)$ & $8.81(8.5-9.17)$ & 0.09 \\
\hline Statins therapy prior to admission, n (\%) & $88(80.7)$ & $1015(82.4)$ & 0.9 \\
\hline Fibrates therapy prior to admission, $\mathrm{n}(\%)$ & $3(2.7)$ & $33(2.7)$ & 0.7 \\
\hline All-cause mortality, $\mathrm{n}(\%)$ & $15(13.7)$ & $180(14.6)$ & 0.8 \\
\hline
\end{tabular}

aData are shown as median (interquartile range, IQR) unless otherwise indicated. $P<0.05$ was considered significant Abbreviations: see Table 1

Table 3. Predictors of MACE in one year follow-up (univariate regression analysis)

\begin{tabular}{|c|c|c|c|}
\hline Predictors of MACE in 1-year follow-up & OR & $95 \% \mathrm{Cl}$ & P-value \\
\hline CAD diagnosed prior to admission & 1.81 & $1.22-2.69$ & $<0.01$ \\
\hline eGFR, $\mathrm{ml} / \mathrm{min} / 1.73 \mathrm{~m}^{2}$ & 0.98 & $0.97-0.99$ & 0.03 \\
\hline $\mathrm{LDL}-\mathrm{C}, \mathrm{mmol} / \mathrm{l}$ & 0.73 & $0.59-0.89$ & $<0.01$ \\
\hline $\mathrm{TC}, \mathrm{mmol} / \mathrm{l}$ & 0.77 & $0.64-0.92$ & $<0.01$ \\
\hline
\end{tabular}

Abbreviations: $\mathrm{Cl}$, confidence interval; OR, odds ratio; other — see Table 1

Table 4. Predictors of MACE in one year follow-up after exclusion of patients with higher FGL (univariate regression analysis)

\begin{tabular}{l|c|c}
\multicolumn{1}{c|}{ Predictors of MACE in 1-year follow-up } & OR & 95\% Cl \\
\hline CAD diagnosed prior to admission & 1.69 & $1.06-2.69$ \\
$\mathrm{eGFR}, \mathrm{ml} / \mathrm{min} / 1.73 \mathrm{~m}^{2}$ & 0.98 & $0.96-0.99$ \\
$\mathrm{LDL}-\mathrm{C}, \mathrm{mmol} / \mathrm{I}$ & 0.6 & $0.46-0.78$ \\
$\mathrm{TC}, \mathrm{mmol} / \mathrm{I}$ & 0.62 & $0.51-0.82$ \\
\hline
\end{tabular}

Abbreviations: see Table 1 and Table 3

of the TyG index between those 2 groups: 8.7 (8.4-9) in the lower FGL group, versus $9.17(8.86-9.5)$ in the higher one $(P<0.01)$. There was, however, no significant difference between glycemic control status during hospitalization and incidence of MACE at a 1-year follow-up. MACE occurred in $7.68 \%(n=77)$ of patients with lower FGL and in $9.47 \%$ $(n=32)$ of those with potential glucose metabolic disorder $(P=0.29)$. Additionally, after excluding from the analysis the patients with higher FGL, only CAD diagnosed prior to admission, eGFR, LDL-C and TC were statistically significant predictors of MACE in univariate regression analysis (Table 4). The TyG index value was insignificant $(P=0.12)$.

\section{Univariate and multivariable regression analysis of one-year mortality}

The all-cause mortality rate at a 1 -year follow-up was $14.5 \%$ $(n=195)$ for the whole study group, whereas in-hospital mortality was $1.6 \%(n=22)$. In univariate regression analysis, the TyG index value appeared to be an irrelevant indicator of all-cause mortality $(P=0.25)$, whereas age, BMI, Gensini score, eGFR, LDL-C, and TC were statistically significant. Finally, multivariable regression analysis showed that only age was an independent predictor of all-cause mortality at a 1-year follow-up (OR, 1.1; $95 \% \mathrm{Cl}$, 1.06-1.13; $P<0.01)$. Predictors of all-cause mortality are shown in Table 5.

\section{DISCUSSION}

To the best of our knowledge, this study is the first that assesses the TyG index, measured during acute MI among non-diabetic patients, as a potential predictor of MACE and all-cause mortality at a 1-year follow-up. Previously, this metabolic marker was used as an easily accessible indicator of insulin resistance [9], a predictor of diabetes [10], and 
Table 5. Predictors of all-cause mortality in one year follow-up (univariate regression analysis)

\begin{tabular}{l|ccc} 
Predictors of all-cause mortality at 1-year follow-up & OR & 95\% Cl & P-value \\
Age & 1.08 & $1.07-1.1$ & $0.87-0.94$ \\
BMI & 0.91 & $1-1.1$ & $<0.01$ \\
Gensini score & 1.01 & $0.96-0.98$ & $<0.01$ \\
eGFR, $\mathrm{ml} / \mathrm{min} / 1.73 \mathrm{~m}^{2}$ & 0.97 & $0.59-0.81$ & $<0.01$ \\
$\mathrm{LDL}-\mathrm{C}, \mathrm{mmol} / \mathrm{l}$ & 0.7 & $0.65-0.87$ & $<0.01$ \\
$\mathrm{TC}, \mathrm{mmol} / \mathrm{l}$ & 0.76 & $<0.01$ & \\
\hline
\end{tabular}

Abbreviations: see Table 1 and Table 3

Table 6. Medical treatment at discharge

\begin{tabular}{l|c}
\hline Medical treatment at discharge & Number of patients (\%) \\
\hline Statins, $\mathrm{n}(\%)$ & $1332(99.4)$ \\
Ezetimibe, $\mathrm{n}(\%)$ & $166(12.4)$ \\
Fibrates, $\mathrm{n}(\%)$ & $3(0.2)$ \\
ACEl, $\mathrm{n}(\%)$ & $575(42.9)$ \\
ARB, $\mathrm{n}(\%)$ & $324(24.2)$ \\
$\beta$-adrenolytics, $\mathrm{n}(\%)$ & $1139(85)$ \\
Calcium blockers, $\mathrm{n}(\%)$ & $753(56.2)$ \\
Diuretics, $\mathrm{n}(\%)$ & $624(46.6)$ \\
ASA, $\mathrm{n}(\%)$ & $1338(99.8)$ \\
Clopidogrel, $\mathrm{n}(\%)$ & $1170(87.3)$ \\
Prasugrel/ticagrelor, $\mathrm{n}(\%)$ & $168(12.7)$ \\
\hline
\end{tabular}

Abbreviations: see Table 1

a biomarker of glycemic control in type 2 diabetes mellitus [11]. Since the TyG index is a quite novel IR marker, there is no internationally recognized cut-off value. Unger et al. [12] suggested that this value for metabolic syndrome in the general population was 8.8 in men and 8.7 in women, and in the study by Lee et al. [13], where the cut-off value for the TyG index was set at 8.8, this marker was a statistically significant predictor for incidental diabetes in 4-year follow-up. For the current study, the population's median TyG index value was 8.8 , which may suggest a high incidence of IR among patients with MI.

In many patients with MI, the level of fasting glucose is elevated and called "stress hyperglycemia". This condition usually occurs in critically ill patients without diabetes mellitus diagnosed prior to admission [14, 15]. It appears to be connected with a stress mechanism, which is associated with steroid hormones, temporary IR, and a high level of free fatty acids [16]. According to the American Diabetes Association, stress hyperglycemia in hospitalized patients is related to a random glucose level greater than $7.8 \mathrm{mmol} / \mathrm{l}$ at any time [17]. In our research, this condition occurred in $25.2 \%$ of patients. There was no correlation between higher glucose level and incidence of MACE at 1-year follow-up. Furthermore, even after excluding from the analysis the patients with higher FGL, the TyG index, which is directly related to levels of TG and glucose, was not a predictor of MACE.

The usefulness of the TyG index as a predictor of cardiovascular events has previously been investigated in several studies, mostly among healthy individuals or patients with stable CAD.
A recent Chinese retrospective study [18] among 6076 healthy individuals aged over 60 years showed in a 6-year follow-up that a higher risk of CAD events was associated with an increasing value of the TyG index. Another study on that subject, conducted by Park et al. [19] and performed among healthy individuals with no traditional cardiovascular risk factors, showed that a TyG index value over 8.48 was a predictor of CAD. Finally, in an Iranian study [20], the risk of developing CAD increased with increasing quintiles of the TyG index in a long-term follow-up period (16 years).

To the best of our knowledge, little is known about the predictive value of the TyG index in patients with MI. Luo et al. [21] conducted a study on patients with STEMI, undergoing percutaneous coronary intervention, to assess the clinical outcomes of that marker during a follow-up period of 1 year. Those clinical outcomes were defined as major adverse cardiac and cerebrovascular events (MACCE) and included all-cause death, target vessel revascularization, MI, unstable angina pectoris, heart failure, stroke, and transient cerebral ischemia. In that study, patients were divided into 4 groups according to TyG-index quartiles. The incidence of MACCE and all-cause mortality was higher among patients with TyG index values in the highest quartile. Analysis of the predictors of MACCE showed statistical significance for a TyG index value $\geq 9.098$, age, hypertension, diabetes, eGFR, number of implanted stents, and multivessel CAD in univariate analysis. In multivariable analysis, however, only a TyG index value $\geq 9.608$ and the number of implanted stents were significant.

In our analysis, on the other hand, the TyG index value was not significant in univariate regression analysis $(P=0.06)$. In addition, in the multivariable model, only CAD diagnosed prior to admission was relevant (OR, 1.54; 95\% $\mathrm{Cl}, 1.02-2.32 ; P=0.03)$.

In the study by Luo et al. [21], the percentage of patients with incidence of MACCE was higher than in our study $-34.3 \%$ vs. $8.13 \%$. Moreover, patients in the MACCE group had higher mean values of FGL $(9$, standard deviation $[S D]=4.2 \mathrm{mmol} / \mathrm{l}$ vs. median value of 6.9 [5.9-8] $\mathrm{mmol} / \mathrm{l}$ in our study), and $31.2 \%$ of them had diabetes. Furthermore, those patients had higher values of LDL-C, TC, and TG (mean value $-1.9[\mathrm{SD}=1.6] \mathrm{mmol} / \mathrm{l}$ vs. median value of 1.13 [0.9-1.44] mmol/l). Consequently, their TyG index value was higher, with a mean value of $10.076(S D=0.483)$ 
in the highest quartile group. Additionally, in that research, only $2.4 \%$ of patients with incidence of MACE had been diagnosed with CAD prior to admission, whereas in our study, this was $46.8 \%$. Both study populations were similar concerning age, BMI, and the proportion of males. Finally, no correlation between 1-year mortality and the TyG index was found in our report, whereas in the study by Luo et al. [21] that correlation was statistically significant.

In another Chinese study presented by Mao et al. [22], patients with NSTEMI were initially divided into 2 groups according to their TyG index value, these being low $(<8.8)$ and high (>8.8) scores. In that study, more than half of the patients had diabetes or glucose metabolism disorder. Additionally, the incidence of MACE. including cardiac death, nonfatal myocardial infarction, target vessel revascularization, congestive heart failure, and nonfatal stroke, was higher in the high TyG index group at a 1-year follow-up (12.8\% vs. $22.8 \%$; $P<0.01)$.

To deepen the analysis, Mao [22] divided patients into 4 groups, depending on the TyG index value and the occurrence of glucose metabolism disorder. There was a statistically significant difference between the incidence of MACE among the patients without glucose metabolism disorder with low (10.7\%) and high (33.8\%) TyG index values. Finally, in univariate analysis, the TyG index was significantly associated with MACE (hazard ratio [HR], 1.951; 95\% Cl, 1.416-2.688; $P<0.01)$. Furthermore, in the multivariable model, the TyG index also remained an independent predictor of MACE. In the Mao [22] research, the study group was not divided according to the incidence of MACE, so a simple comparison with our study is difficult to perform. In a relatively small population of 438 patients, the incidence of MACE was $17.8 \%$, whereas in our population of 1340 patients, MACE occurred only in $8.13 \%$.

On the other hand, a simple correlation of the value of the TyG Index with the incidence of atherosclerosis, its severity, and incidence of MACE, is questionable. Alizargar et al. [23], in their article assessing the practical value of the TyG index, emphasize that using this marker can be easily biased by hyperlipidemia, diabetes, or other glucose metabolic disorders, as the TyG index has a direct relationship with levels of TG and glucose (based on the TyG index formula). In conclusion, these factors should be carefully considered to justify the use of the TyG index as a biomarker. In the Polish population, we can still observe insufficient adherence to guidelines concerning the proper level of glucose, lipid profile, blood pressure, BMI, physical activity, and smoking [24]; therefore, the potential use of the TyG index might be limited.

Dziedzic et al. [25] in their study concerning educational programs among Polish elderly patients showed that several training meetings performed to change lifestyle in that group had an impact on the lipid profile of the participants, particularly concerning the level of TG $(P=0.02)$. Finally, Wybraniec et al. [26] revealed that patients enrolled on a similar program (Managed Care After Acute Myocardial Infarction Program) had a lower rate of MACE at a 1-year follow-up (11.3\% vs. 19.1\%; $P=0.0006)$. We believe that similar programs should be implemented in order to properly manage basic cardiological risk factors, reduce the rate of MACE, and improve patient survival.

Vega et al. [27] also presented concerns concerning the predictive value of the TyG index. In that study, this index was a positive predictor of coronary heart disease, cardiovascular disease, and all-cause mortality, but only unadjusted and, after adjustment, for age, smoking, BMI, and systolic blood pressure. After an additional adjustment for non-HDL-C level, the HR was lower - 0.83 for coronary heart disease, 0.89 for cardiovascular disease, and 0.89 for all-cause mortality. Our findings correspond with Vega's conclusions that the TyG index does not predict all-cause mortality.

In our opinion, this metabolic biomarker should not be used as a predictor of clinical outcomes among non-diabetic patients with Ml for several reasons. Firstly, the TyG index has a direct relationship with glycemia which can be labile in acute conditions such as MI. Secondly, in our study, the TyG index was not a predictor of MACE even after we excluded from the study the group of patients with $\mathrm{FGL}$ $\geq 7.8 \mathrm{mmol} / \mathrm{l}$. Finally, there was no association between the TyG index value and all-cause mortality.

We should also briefly discuss other predictors that were statistically significant in our study. Surprisingly, LDL-C and TC were negative predictors of MACE and all-cause mortality. We believe that this was caused by the fact that the patients with incidence of MACE had lower values of those parameters as compared with those without it. Moreover, the patients with MACE had lower concentrations of non-HDL-C and TG. Even though there was no difference between the use of statins and fibrates prior to admission among the patients with and without the incidence of MACE at 1-year follow- up, we can assume that the lipid-lowering therapy of those patients with the incidence of MACE was more intensive, and their compliance with prescribed therapy was better because $46.8 \%$ of them were previously diagnosed with CAD. Unfortunately, we are unable to verify those assumptions. Moreover, data concerning lipid-lowering therapy was obtained from anamnesis and the patients' compliance with prescribed treatment remains unknown.

\section{Study limitations}

This study has several limitations. Firstly, a relatively short follow-up period. Secondly, insufficient information concerning the patients' compliance with prescribed therapy and data regarding changes in lipid-lowering therapy, which might have improved cardiovascular outcomes of the patients [28] and affected our study. Thirdly, we had no information concerning the date of MACE. Finally, short follow-up and unknown causes of death in patients without 1-year survival represented other study limitations. 


\section{CONCLUSIONS}

The TyG index does not appear to be a predictor of MACE among non-diabetic patients with MI. We believe that its potential use in acute conditions is limited by acute metabolic changes accompanying $\mathrm{Ml}$, and it does not help to identify non-diabetic individuals at a greater risk of poor clinical outcomes. Furthermore, no association between the TyG index value and all-cause mortality at a 1-year follow-up also reflects the questionable clinical value of that parameter. Moreover, comprehensive evaluation of cardiovascular risk factors should focus primarily on basic risk factors. Additional markers may be useful but after the effective management of these risk factors.

\section{Article information}

Acknowledgments: The study was supported by a grant from JagielIonian University Medical College N41/DBS/000098; to EK).

\section{Conflict of interest: None declared.}

Open access: This article is available in open access under Creative Common Attribution-Non-Commercial-No Derivatives 4.0 International (CC BY-NC-ND 4.0) license, allowing to download articles and share them with others as long as they credit the authors and the publisher, but without permission to change them in any way or use them commercially. For commercial use, please contact the journal office at kardiologiapolska@ptkardio.pl.

How to cite: Drwiła D, Rostoff P, Gajos G, et al. Prognostic value of the triglyceride-glucose index among non-diabetic patients with acute myocardial infarction at one-year follow-up. Kardiol Pol. 2021; 79(10): 1116-1123, doi: 10.33963/KP.a2021.0104.

\section{REFERENCES}

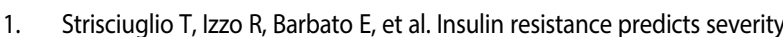
of coronary atherosclerotic disease in non-diabetic patients. J Clin Med. 2020; 9(7): 2144, doi: 10.3390/jcm9072144, indexed in Pubmed: 32646007.

2. Cho YR, Ann SH, Won KB, et al. Association between insulin resistance, hyperglycemia, and coronary artery disease according to the presence of diabetes. Sci Rep. 2019; 9(1): 6129, doi: 10.1038/s41598-019-42700-1, indexed in Pubmed: 31477741.

3. Du T, Yuan G, Zhang M, et al. Clinical usefulness of lipid ratios, visceral adiposity indicators, and the triglycerides and glucose index as risk markers of insulin resistance. Cardiovasc Diabetol. 2014; 13: 146, doi: 10.1186/s12933-014-0146-3, indexed in Pubmed: 25326814.

4. Gensini GG. A more meaningful scoring system for determining the severity of coronary heart disease. Am J Cardiol. 1983; 51(3): 606, doi: 10.1016/s0002-9149(83)80105-2, indexed in Pubmed: 6823874.

5. Guerrero-Romero F, Simental-Mendía LE, González-Ortiz M, et al. The product of triglycerides and glucose, a simple measure of insulin sensitivity. Comparison with the euglycemic-hyperinsulinemic clamp. J Clin Endocrinol Metab. 2010; 95(7): 3347-3351, doi: 10.1210/jc.2010-0288, indexed in Pubmed: 20484475.

6. White HD, Thygesen $K$, Alpert JS, et al. Writing Group on the Joint ESC/ACCF/AHA/WHFTaskForce for the Universal Definition of Myocardial Infarction, ESC Committee for Practice Guidelines (CPG). Third universal definition of myocardial infarction. Eur Heart J. 2012; 33(20): 2551-2567, doi: 10.1093/eurheartj/ehs184, indexed in Pubmed: 22922414.

7. Thygesen K, Alpert JS, Jaffe AS, et al. ESC Scientific Document Group. Fourth universal definition of myocardial infarction. Eur Heart J. 2019; 40(3): 237-269, doi: 10.1093/eurheartj/ehy462.

8. Rydén L, Grant PJ, Anker SD, et al. Authors/Task Force Members, ESC Committee for Practice Guidelines (CPG), Document Reviewers. ESC Guidelines on diabetes, pre-diabetes, and cardiovascular diseases developed in collaboration with the EASD: the Task Force on diabetes, pre-diabetes, and cardiovascular diseases of the European Society of Cardiology (ESC) and developed in collaboration with the European Association for the
Study of Diabetes (EASD). Eur Heart J. 2013; 34(39): 3035-3087, doi: 10.1093/eurheartj/eht108, indexed in Pubmed: 23996285.

9. Lim J, Kim J, Koo SH, et al. Comparison of triglyceride glucose index, and related parameters to predict insulin resistance in Korean adults: An analysis of the 2007-2010 Korean National Health and Nutrition Examination Survey. PLoS One. 2019; 14(3): e0212963, doi: 10.1371/journal. pone.0212963, indexed in Pubmed: 30845237.

10. Chamroonkiadtikun $P$, Ananchaisarp T, Wanichanon W. The triglyceride-glucose index, a predictor of type 2 diabetes development: A retrospective cohort study. Prim Care Diabetes. 2020; 14(2): 161-167, doi: 10.1016/j.pcd.2019.08.004, indexed in Pubmed: 31466834.

11. Babic N, Valjevac A, Zaciragic A, et al. The triglyceride/hdl ratio and triglyceride glucose index as predictors of glycemic control in patients with diabetes mellitus type 2. Med Arch. 2019; 73(3): 163-168, doi: 10.5455/medarh.2019.73.163-168, indexed in Pubmed: 31404127.

12. Unger G, Benozzi SF, Perruzza F, et al. Triglycerides and glucose index: a useful indicator of insulin resistance. Endocrinol Nutr. 2014;61(10):533540, doi: 10.1016/j.endonu.2014.06.009, indexed in Pubmed: 25174769.

13. Lee DaY, Lee ES, Kim JiH, et al. Predictive value of triglyceride glucose index for the risk of incident diabetes: a 4-year retrospective longitudinal study. PLoS One. 2016; 11(9): e0163465, doi: 10.1371/journal.pone.0163465, indexed in Pubmed: 27682598.

14. Mizock BA. Alterations in fuel metabolism in critical illness: hyperglycaemia. Best Pract Res Clin Endocrinol Metab. 2001; 15(4): 533-551, doi: 10.1053/beem.2001.0168, indexed in Pubmed: 11800522.

15. Andres $M$, Legutko J, Konduracka $E$, et al. The significance of dynamics of ST segment changes when assessing the effectiveness of mechanical reperfusion of the myocardium in hyperglycaemic patients with acute myocardial infarction with persistent ST-segment elevation. J Integrative Cardiol. 2020; 6(1), doi: 10.15761/jic.1000282.

16. Wu Y, Ding Y, Tanaka Y, et al. Risk factors contributing to type 2 diabetes and recent advances in the treatment and prevention. Int J Med Sci. 2014; 11(11): 1185-1200, doi: 10.7150/ijms.10001, indexed in Pubmed: 25249787.

17. American Diabetes Association. Classification and diagnosis of diabetes: standards of medical care in diabetes - 2019. Diabetes Care. 2019; 42(Suppl 1): S13-S28, doi: 10.2337/dc19-s002.

18. Li S, Guo B, Chen $\mathrm{H}$, et al. The role of the triglyceride (triacylglycerol) glucose index in the development of cardiovascular events: a retrospective cohort analysis. Sci Rep. 2019; 9(1): 7320, doi: 10.1038/s41598-019-437765, indexed in Pubmed: 31086234.

19. Park GM, Cho YR, Won KB, et al. Triglyceride glucose index is a useful marker for predicting subclinical coronary artery disease in the absence of traditional risk factors. Lipids Health Dis. 2020; 19(1): 7, doi: 10.1186/s12944-020-1187-0, indexed in Pubmed: 31937313.

20. Barzegar N, Tohidi M, Hasheminia M, et al. The impact of triglyceride-glucose index on incident cardiovascular events during 16 years of follow-up: Tehran Lipid and Glucose Study. Cardiovasc Diabetol. 2020; 19(1): 155, doi: 10.1186/s12933-020-01121-5, indexed in Pubmed: 32993633.

21. Luo E, Wang D, Yan G, et al. High triglyceride-glucose index is associated with poor prognosis in patients with acute ST-elevation myocardial infarction after percutaneous coronary intervention. Cardiovasc Diabetol. 2019; 18(1): 150, doi: 10.1186/s12933-019-0957-3, indexed in Pubmed: 31722708.

22. Mao Qi, Zhou D, Li Y, et al. The triglyceride-glucose index predicts coronary artery disease severity and cardiovascular outcomes in patients with non-ST-segment elevation acute coronary syndrome. Dis Markers. 2019; 2019: 6891537, doi: 10.1155/2019/6891537, indexed in Pubmed: 31281548.

23. Alizargar J, Bai $\mathrm{CH}$, Hsieh NC, et al. Use of the triglyceride-glucose index (TyG) in cardiovascular disease patients. Cardiovasc Diabetol. 2020; 19(1): 8, doi: 10.1186/s12933-019-0982-2, indexed in Pubmed: 31941513.

24. Krawczyk-Ożóg A, Płotek A, Hołda M, et al. Assessment of the implementation level of the guidelines for secondary prevention of cardiovascular disease in everyday clinical practice. Kardiol Pol. 2021; 79(4):434-441, doi: 10.33963/KP.15856, indexed in Pubmed: 33687867.

25. Dziedzic B, Imiela J, Sienkiewicz Z, et al. Educational program can favorably change the lipid profile in older people diagnosed with ischemic heart disease. Kardiol Pol. 2019; 77(7-8): 719-722, doi: 10.33963/KP.14817, indexed in Pubmed: 31066724. 
26. Wybraniec MT, Mizia-Stec K, Gąsior Z, et al. Long-term effects of the Managed Care After Acute Myocardial Infarction program: an update on a complete 1-year follow-up. Kardiol Pol. 2020; 78(5): 458-460, doi: 10.33963/KP.15256, indexed in Pubmed: 32406217.

27. Vega GL, Barlow CE, Grundy SM, et al. Triglyceride-to-high-density-lipoprotein-cholesterol ratio is an index of heart disease mortality and of incidence of type 2 diabetes mellitus in men. J Investig Med. 2014; 62(2):
345-349, doi: 10.2310/JIM.0000000000000044, indexed in Pubmed: 24402298.

28. De Luca L, Corsini A, Uguccioni M, et al. Statins plus ezetimibe in the era of proprotein convertase subtilisin/ kexin type 9 inhibitors. Kardiol Pol. 2020; 78(9): 850-860, doi: 10.33963/KP.15529, indexed in Pubmed: 32716152. 